\title{
HISTÓRIA DA ESCOLARIZAÇÃO DA CRIANÇA POBRE: algumas imbricações entre escola, trabalho infantil e caridade (Rio Grande do Sul, Brasil) ${ }^{1}$
}

\author{
Natália Gil \\ Universidade Federal do Rio Grande do Sul - UFRGS \\ Luísa Grando \\ Universidade Federal do Rio Grande do Sul - UFRGS
}

\begin{abstract}
Resumo
Neste artigo apresentamos uma análise histórica das menções à escolarização das crianças pobres no jornal A Federação, que circulou no Rio Grande do Sul entre 1884 e 1937 configurando-se como importante meio de comunicação representativo do pensamento das elites locais. O exame da documentação permitiu observar a predominância das questões que se referem à premência do trabalho na vida das crianças pobres e as consequências para sua escolarização, como a necessidade de frequentar as aulas no período noturno. Configura-se, então, uma das formas sutis de exclusão escolar desse grupo populacional, não pelo impedimento da matrícula, mas pela diferenciação dos estabelecimentos de ensino e dos percursos escolares. Também se destacaram as notícias de ações caritativas que pretendiam contribuir no provimento de condições para o acesso da criança pobre à escola. Nesse sentido, o foco esteve nas caixas escolares, que recebiam contribuições financeiras, de alunos abastados e demais cidadãos, destinadas à compra, sobretudo, de roupas e calçados para os alunos pobres. Mais do que uma política de garantia do direito à educação, tal iniciativa configurou-se em forma de inserção controlada dos pobres nos projetos de sociedade desenhados pelas elites.
\end{abstract}

Palavras-chave: Imprensa periódica; escola noturna; caixa escolar; pobreza; história da infância.

\begin{abstract}
In this article we present a historical analysis of the mentions of the schooling of poor children in the newspaper A Federação, which circulated in Rio Grande do Sul between 1884 and 1937 configuring itself as an important means of communication representative of the thinking of local elites. The scrutiny of the documentation made it possible to observe the predominance of questions that refer to the urgency of work in the lives of poor children and its consequences for their schooling, such as the need to attend classes in the evening. Thus, one of the subtle forms of school exclusion of this population group is shaped, not by preventing enrollment, but by differentiating educational institutions and school paths. It has been also highlighted the news of charitable actions that aimed to contribute to providing conditions for access to school for poor children. In this sense, the focus was on deposit boxes, which received financial contributions from wealthy students and other citizens, intended to buy, above all, clothes and shoes for poor students. More than a policy of guaranteeing the right to education, this initiative was shaped in the form of controlled insertion of the poor in the projects of society designed by the elites.
\end{abstract}

Keywords: Periodical press; evening schools; deposit box; poverty; history of childhood. 
Em escala diminuta embora, sentireis aqui a assistencia integral à creança pobre [...]. No primeiro dia, entram aqui com typos acabados de carentes de alimentação, escassa no lar de miseria, em quantidade e qualidade, para em breve, augmentarlhes o peso e a resistencia organica. A principio, anaphabetos, vêm, logo, illuminar-lhes a inteligencia adormecida, os clarões das primeiras letras. Como que selvagens, de inicio, desconhecido até o nome de Deus, em poucos dias, a acção milagrosa deste verdadeiro asylo diurno consegue ouvir-lhes sinceras e humildes orações (A Federação, 18/08/1934, p. 3)

A educação da criança pobre é tema recorrente na documentação do século XIX e das primeiras décadas do século XX no Brasil. A atribuição auto instituída pela elite brasileira de construir um novo país, buscando tornar a sociedade civilizada e imprimindo os ritmos do progresso à nação, esteve na origem da proposição de criação de escolas de primeiras letras destinadas ao povo, bem como na defesa de proteção e educação da infância desvalida. Também a preocupação em evitar os riscos representados pelo descontrole de uma população desocupada e ignorante compareceu nos argumentos postos em circulação para a defesa da educação dos pobres. Crianças e adultos pobres foram, historicamente, destinatários tanto de iniciativas caritativas quanto de ações de controle e contenção sendo, portanto, variada, polissêmica e, por vezes, contraditória a menção ao pobre e à pobreza na história da educação brasileira.

A intenção neste artigo é contribuir na tarefa de problematizar a polissemia do termo pobre nas pesquisas em História da Educação, bem como apresentar o modo pelo qual esse termo aparece em associação com a escola na documentação do Rio Grande do Sul entre o final do século XIX e a primeira metade do século XX. Feita a análise da documentação empírica, dois aspectos se destacaram. De um lado, a centralidade do trabalho, que é expressiva nas vivências dos pobres, inclusive as crianças, bem como suas implicações na escolarização dessa população. De outro lado, o vínculo entre a infância pobre e a caridade, como “ajuda” aos necessitados que é considerada uma prevenção aos riscos que os pobres representam à ordem, na perspectiva das sociedades burguesas.

$\mathrm{O}$ estudo foi realizado assumindo como fonte principal $^{2}$ o jornal A Federação, que circulou no Rio Grande do Sul entre 1884 e 1937. Tendo sido criado em Porto Alegre por defensores dos ideais republicanos, liberais e abolicionistas do Partido Republicano RioGrandense (PRR), após instituída a República, o periódico passou a representar o grupo político hegemônico no estado. Em 1937, com a extinção dos partidos políticos pelo Estado Novo, deixou de ser publicado. Ao longo de todo o período em que esteve em circulação, está presente a perspectiva de que era preciso dar atenção à educação de crianças e adultos “vítimas do desamparo e da ignorância”. Prevalecia a compreensão de que as iniciativas de alfabetização dos pobres contribuiriam "para tirá-los da cegueira da ignorância como também para formação de cidadãos dignos da Pátria” (A Federação, 29/09/1933, p. 4). Assim, a análise detida das publicações desse jornal permitiu identificar quais temáticas prevaleciam nos discursos das elites no que se refere às relações entre a criança pobre e a escola, tema 
central dos nossos esforços investigativos. Além disso, foram consultadas pontualmente outras fontes na medida em que ampliavam a compreensão da questão em destaque e/ou completavam informações, notadamente a legislação, relatórios oficiais e outros jornais locais. A periodização acompanha aquela em que o periódico esteve em circulação.

\section{A criança pobre na historiografia da educação}

A palavra pobre remete imediatamente à ideia de escassez de recursos financeiros para o sustento de si e de sua família. No Dicionário Houaiss (2009, p. 1512, negrito no original) consta a seguinte designação:

Pobre adj. 1. desprovido ou mal provido do necessário; de poucas posses; que não tem recursos próprios 2. que aparenta ou revela pobreza [não estava malvestido, mas tinha um aspecto p.] 3. maldotado, pouco favorecido [era um sujeito p. de imaginação] 4. pouco produtivo, estéril [terra p.] 5. digno de lástima; que inspira compaixão [p. homem, perdeu tudo em dois dias] s. 6. pessoa de parcos recursos 7. pessoa que pede esmolas; mendigo, pedinte [...].

Se recuarmos no tempo, encontramos significado muito semelhante. Por exemplo, o Diccionario da Lingua Brasileira por Luiz Maria da Silva Pinto (1832, p. 674) traz a seguinte definição: "Pobre adj. Que não tem o necessário para viver. Que tem poucas posses. De pouco valor. Infeliz. Como subst. O que pede pelas portas. Sup. issimo.”. É preciso, no entanto, atentar para o fato de que a definição presente nos dicionários, embora busque apreender a multiplicidade de significados das palavras em determinado tempo e espaço, não dá conta de apresentar todas as acepções que circulam socialmente em dado período. Nesse sentido, deve-se reconhecer que o termo em análise corresponde a um conceito elástico, abarcando expressões que se referem aos pobres, subalternos, populares, proletários, ou seja, aqueles considerados protagonistas da “questão social”. Como ressalta Sandra Pesavento (1994, p. 89):

Enunciada enquanto problema, a questão social suscitará a elaboração de discursos científicos que a descrevem, analisam e despertam estratégias de abordagem para atingir resultados satisfatórios. É assim que se articula o discurso médico e higienista, o discurso jurídico e criminológico, o discurso técnico e estético.

Aqueles que elaboravam e divulgavam preceitos higienistas identificavam nos pobres um vetor de transmissão de doenças e suas moradias, notadamente os cortiços que se multiplicavam nos grandes centros urbanos no final do século XIX, eram vistos como espaços propícios ao surgimento de epidemias. Além disso, a antropometria, associada à criminologia, buscou estabelecer um repertório de traços físicos supostamente capazes de predizer a tendência ao crime, traços esses que sugeriam que a população pobre representava 
grande perigo. Nesse sentido, importa destacar que, para a elite do período, "os pobres poderiam ser perigosos, não apenas em função de sua sujeira, como focos potenciais de doenças (Faure, 1977), mas pelas suas características genéticas, que os predispunham à degeneração e a toda sorte de crime (Dumont, 1984)” (PESAVENTO, 1994, p. 10). Há, ainda, o preconceito racial a considerar. Sidney Chalhoub (1996), a partir do estudo da história do combate aos cortiços no Rio de Janeiro ainda no período imperial, contribuiu significativamente para o conhecimento desse tema. Como ressalta Fabiano Quadros Rückert (2019, p. 333), as análises de Chalhoub permitem notar que

o discurso contra o comportamento dos que viviam nos cortiços, apesar de expressar preocupações sanitárias, incorporou preconceitos raciais de uma sociedade escravista e manifestou uma crescente desconfiança da elite a respeito dos negros e mulatos que formavam a "arraia miúda".

Isso nos conduz ao reconhecimento de que a historiografia tem permitido identificar outros sentidos socialmente atribuídos ao termo. Se, objetivamente, pobre é aquele que encontra dificuldade ou impossibilidade financeira de manter seu sustento e o de sua família, é preciso considerar também que

é um fenômeno que ganha forma, percepção e significado a partir das relações sociais e, consequentemente, o seu estudo demanda a observação de diversos fatores, dentre os quais importa destacarmos o modelo econômico existente em uma determinada sociedade, as práticas de apropriação dos recursos naturais, a distribuição dos resultados do trabalho e as representações historicamente construídas a respeito dos pobres (RÜCKERT, 2019, p. 317).

Assim, fazer uma história da pobreza remete à atenção e ao detalhamento necessário das especificidades das diversas realidades apreendidas nas fontes. Uma das especificações diz respeito às características da pobreza no meio urbano. Milton Santos (2013) sublinha que nas cidades o uso do solo atende a interesses que não incluem o cultivo da terra para itens de subsistência, o que impede à população pobre a garantia do essencial à alimentação. Também a especulação imobiliária penaliza essa população já que os valores dos aluguéis tendem a subir excessivamente nas regiões mais centrais e desenvolvidas, obrigando a busca por moradia em regiões periféricas, distantes de seus locais de trabalho e nas quais a melhoria de infraestrutura tarda a chegar. Por fim, há os efeitos de dispositivos jurídicos e institucionais que disciplinam a organização e circulação nas cidades, fazendo prevalecer valores burgueses no uso do espaço e nas regras de convívio, enquanto proíbem e criminalizam práticas culturais de grupos subalternizados. Fabiano Quadros Rückert (2019, p. 333) identifica alguns estudos que assumem esse tema como foco central, contudo, enfatiza que "o conhecimento historiográfico sobre a pobreza urbana no Brasil na transição do século XIX para o XX ainda é incipiente”.

Outro aspecto que merece destaque é o vínculo incontornável dos pobres com a atividade laboral. Por disporem de parcos recursos, seu acesso ao consumo é limitado, sendo a 
subsistência e a moradia problemas recorrentes. Isso os obriga a trabalhar nas ocupações preteridas pelos grupos sociais privilegiados, desempenhando as tarefas menos qualificadas, embora frequentemente sejam atividades essenciais ao funcionamento da sociedade. Além disso, muitas vezes, as atividades que realizam não compõem o mercado formal de trabalho. Interessante notar que historicamente a construção da burguesia introduziu uma ambiguidade na associação entre pobreza e trabalho. Se, por um lado, o trabalho foi erigido como garantia de honra e dignidade, quanto à população pobre pairava a desconfiança sobre se estaria qualificada para o exercício de tais valores. Disso a compreensão prevalecente nos discursos das elites de que "os desvalidos só se converterão em trabalhadores ordeiros se sobre eles exercer-se feroz vigilância, disciplinando corpos e mentes, pois são grandes os riscos de caírem na contravenção ou apresentarem comportamentos desviantes” (PESAVENTO, 1994, p. 10).

De um lado, os pobres são os operários, cumprem extensas jornadas laborais na fábrica, constituída como espaço de controle e disciplinamento capaz de produzir determinados tipos de trabalhadores. Mas os pobres também são aqueles que escapam ao controle desses espaços formais de trabalho e vagam pelas cidades, realizando atividades que garantem algum mínimo sustento com pouca regularidade, usufruindo de certas liberdades no uso do tempo consideradas inaceitáveis na ordem burguesa. Daí, por exemplo, a promulgação de documentos tais como o Código de Posturas Municipais (o de Porto Alegre, por exemplo, é datado de 1893) e a criminalização da mendicância, da vagabundagem, da prostituição, como se observa na legislação de diversas localidades e como é possível verificar pelos relatórios policiais. Sandra Pesavento (1994, p. 112), referindo-se à história de Porto Alegre, destaca que

os elementos à margem deste mercado [livre de trabalho] eram desviantes, perigosos e suspeitos. Se as próprias classes trabalhadoras eram potencialmente perigosas, o que dizer da massa mais ampla de subalternos, que vivia de expedientes, biscates ou sei lá o quê?

Além disso, os pobres podem ser também os “desvalidos da sorte”, os incapazes, os aleijados e os débeis para os quais destina-se, sobretudo, a ação caritativa cristã. Todos esses aspectos comparecem, resguardadas as especificidades, também na história da educação da criança pobre que figura nos projetos de governo como aquela que deve ser atendida pela caridade, ter seus comportamentos controlados e moralizados, além de ser preparada para o trabalho e a obediência às regras.

A moralização e o ajustamento do trabalhador à sociedade estão na origem da criação de escolas profissionalizantes no século XIX. Como destaca Jailson Alves dos Santos (2003, p. 208), no que se refere ao ensino dos ofícios,

permaneceu, nos primórdios do Império, a mentalidade conservadora que havia sido construída ao longo dos três séculos de duração do período colonial: destinar tal ramo do ensino aos humildes, pobres e desvalidos, continuando, portanto, o 
processo discriminatório em relação às ocupações antes atribuídas somente aos escravos.

Mas também foram os imperativos do trabalho que afastaram da escola muitas crianças, fazendo circular a ideia de que as classes trabalhadoras eram ignorantes - e por isso não davam valor ao estudo, permitindo a seus filhos abandonarem os estudos - e contribuindo para dificultar os percursos escolares dessas crianças. A baixa frequência às aulas era um problema recorrentemente mencionado. Por um lado, a ignorância das famílias era a razão indicada em muitos relatórios provinciais para a intermitente presença das crianças na escola, como tem sido evidenciado em vários estudos (VIDAL; SILVA; SÁ, 2013). Considerava-se urgente conscientizar a população sobre a importância de enviar os filhos à instituição escolar. Por outro lado, também era necessário, pretendendo-se viabilizar o projeto de escolarização da infância, criar as condições materiais que permitissem às crianças pobres afastarem-se do trabalho para frequentar as aulas. Cynthia Greive Veiga (2005, p. 87), analisando uma vasta documentação escolar sobre a província de Minas Gerais, identifica

problemas os mais diversos, sendo que no âmbito das autoridades, o tema principal é o problema da infrequência ou frequência irregular das crianças às aulas, seguido de pedidos de material escolar para alunos pobres, relatos sobre a pobreza das famílias, problemas relativos aos professores "que não cumprem seus deveres” e ainda a resistência dos pais em enviarem os filhos à escola.

Cynthia Greive Veiga (2017, p. 1240-1241) destaca, também, que

a institucionalização da escola pública e obrigatória para todas as crianças desde o século XIX, e as dificuldades enfrentadas pelas famílias pobres para enviar seus filhos, em geral devido à necessidade de seu trabalho. Nesse contexto, a qualificação de criança sem escola ou analfabeta passou a compor o espectro de estigmas de inferioridade desses grupos sociais.

As representações da pobreza, além de característica de inferioridade, apresentam recorrentemente também noções associadas a um suposto perigo que justificaria a institucionalização da educação de determinados grupos. Assim, no final do século XIX, como salienta Carmen Sylvia Vidigal Moraes (2000, p. 72),

os receios provocados pelo "aumento extraordinário" de mendicidade, da horda de desocupados e "vadios" - que, apesar da ação da polícia, percorriam "as ruas da cidade implorando a caridade pública" - levam a classe dominante a tomar medidas para coibir a permanência dos “inválidos para o trabalho”. É também providenciada a criação - tanto por parte do Estado como da iniciativa privada de inúmeras instituições de assistência, os denominados asilos: asilos para mendigos, para alienados, para órfãos, para tuberculosos etc. 
Segundo a autora, "o objetivo de isolar do convívio social os indivíduos considerados improdutivos é claramente explicitado nos discursos dos dominantes” (MORAES, 2000, p. 73). A escola, nesse sentido, era proposta como instituição preventiva desse quadro nefasto. Autores como Almeida Junior (1933), por exemplo, que foi professor e diretor do Departamento de Educação em São Paulo na primeira metade do século XX, consideravam que a falta de escolas deixava as crianças entregues ao ócio, vagando pelas ruas, expostas a todo tipo de imoralidades o que as conduzia, se fossem meninos, à delinquência e as meninas, à prostituição. Como sublinham Irma Rizzini e José Gonçalves Gondra (2014, p. 576, itálicos no original), "circulava entre os grupos comprometidos com a 'causa da infância' uma forte crença de que 'a educação é o antídoto da criminalidade', cabendo ao Estado não estender os aparelhos judiciários ou policiais, mas disseminar os aparelhos educativos".

Os temores eugenistas de degenerescência da população e as intenções de moralização não apenas das crianças como também de suas famílias têm, igualmente, comparecido nas pesquisas históricas sobre a educação das crianças pobres no Brasil. Ana Laura Godinho Lima (2018) ressalta que, nas primeiras décadas do século XX, o uso de testes psicológicos aplicados nas escolas tinha o intuito de permitir localizar as crianças ditas anormais que deveriam ser retiradas das salas de aula regulares para receber tratamento especializado. $\mathrm{O}$ estudo das causas da anormalidade passava pela aplicação de testes capazes de quantificar os desempenhos e aptidões dessas crianças, mas também incluía o estudo detalhado de sua biografia e as características do meio familiar em que se inseriam. Nesse sentido, estabeleciase uma forte articulação entre os desajustamentos das crianças na escola e a situação de pobreza em que viviam. É o que se pode notar no caso da criação do Serviço Social, em 1938 pelo governo federal, que previa

[...] a utilização das obras mantidas quer pelos poderes públicos quer pelas entidades privadas para o fim de diminuir ou suprimir as deficiências ou sofrimentos causados pela pobreza ou pela miséria ou oriundos de qualquer outra forma de desajustamento social e de reconduzir tanto o indivíduo como a família, na medida do possível, a um nível satisfatório de existência no meio em que habitam (Decreto-Lei n. 525, de $1^{\text {o }}$ de julho de 1938 apud LIMA, 2018, p. 128).

Moysés Kuhlmann Junior (2003) também tem identificado em seus estudos, no que se refere aos anos finais do século XIX e ao longo de boa parte do século XX, vínculos explícitos entre os projetos de escolarização da primeira infância e as preocupações quanto aos destinos das crianças pobres. A proteção da infância se atrelava ao objetivo de garantir as condições favoráveis ao progresso do país, como se pode notar também na documentação histórica sulrio-grandense. Consta, por exemplo, em 1884, no jornal A Federação que:

O patriotismo náo consiste em dizer nos congressos de protecção á infancia que no Brazil este ramo de serviço é admiravelmente feito, quando todos nós sabemos que desde o exposto até ingênuo, o orphão e o menino pobre todos vivem abandonados, ou ainda pior do que isso, pessimamente protegidos [...] ( $A$ Federação, 04/07/1884, p. 1). 
Selvagens que devem ser civilizados, vagabundos que devem ser controlados, operários que devem ser moralizados, a população pobre foi alvo de iniciativas educativas e disciplinadoras de vários tipos, algumas das quais passavam pela escolarização. Nesse sentido, importa notar a ambiguidade do projeto de construção da nação brasileira e da afirmação dos direitos de cidadania tanto no pós-independência como no início do período republicano: se a escola, nos projetos liberais, deveria ser instituição destinada a todos, no caso brasileiro foram muito presentes as diferenciações das propostas de escolarização em função do público ao qual se destinavam as instituições. Vistos como cidadãos de segunda categoria (PESAVENTO, 1994), aos pobres a proposição de escola seguia critérios distintos daqueles previstos aos grupos privilegiados.

\section{Trabalho e escola na vida da criança pobre}

No Rio Grande do Sul, a circulação de ideias liberais e positivistas entre as elites dirigentes vai determinar a livre iniciativa aos particulares no que se refere à educação e o fomento à expansão das escolas primárias (LUCHESE, 2013). O jornal A Federação se constitui, nesse cenário, como um meio de comunicação importante. Defendia-se, então, a garantia de acesso de todos ao ensino elementar, inclusive para os comprovadamente pobres. É o que se observa em uma notícia sobre as exigências para que as crianças pobres pudessem frequentar a Escola Benjamin Constant:

[...] se acham abertas as inscripções de matriculas nesta Escola para meninos pobres e filhos de operarios. Os requerimentos de matriculas, selladas com sello estadoal, deverão ser acompanhadas dos seguintes documentos: certidão de edade do candidato ou documento equivalente, comprobatoria de sua edade maior de 10 e menor de 15 annos; attestado de que o candidato e o menino pobre, passado pela Intendência Municipal, ou attestado que o mesmo candidato é filho de operario, para que o requerente deverá ajuntar attestado do chefe do estabelecimento ou empresa em que trabalha (A Federação, 04/02/1908, p. 2).

Também nos relatórios do governo do estado se encontram referências sobre a exigência de comprovação de pobreza para receber gratuitamente os livros escolares. Joseane El Hawat (2015, p. 128), ao analisar os regulamentos da instrução de 1872, 1876, 1897 e 1906 referentes ao Rio Grande do Sul, localiza informação de que os livros e demais objetos necessários ao ensino dos meninos pobres seriam custeados pelo estado, mas apenas aos alunos que apresentassem atestado de pobreza. Por exemplo, em 1897, constava que os conselheiros distritais deveriam fornecer às "crianças reconhecidamente pobres, 0 indispensável attestado, a fim de que possa o professor distribuir-lhes livros e o necessário para o ensino” (RIO GRANDE DO SUL, 1907). Mesmo antes, a legislação do Rio Grande do Sul já previa o suprimento das condições para frequência à escola das crianças pobres: 
"Todo o ensino e expediente dentro das escolas será feito a custa dos cofres públicos. Correrãô também pôr conta dos mesmos cofres as despezas de fornecimento de livros e outros objectos necessarios ao ensino, sómente dos meninos pobres” (RIO GRANDE DO SUL, 1876). Interessante observar, ainda, que a legislação previa a escolarização dessas crianças em estabelecimentos particulares para o caso de não existirem escolas mantidas pelo governo:

Quando em uma parochia ou districto por sua pequena população, falta de recursos ou qualquer outra circunstancia, não se reunir numero sufficiente de alumnos que justifique a creação da escola, ou sua continuação, e houver no lugar escola particular, poderá o Director Geral, com approvação do Presidente da Provincia, contractar com o professor d'essa escola a admissão de alumnos pobres mediante uma gratificação de $2 \$ 000$ réis por cada um até o número de vinte, e a de 50\$000 réis mensaes d'esse numero para cima (RIO GRANDE DO SUL, 1876).

Por outro lado, os relatórios da instrução pública indicam algumas tensões em torno da questão, especialmente a necessidade de apresentar o referido atestado. Como destaca Joseane El Hawat (2015, p. 130), os inspetores mencionavam a dificuldade em definir o estado de pobreza dos alunos, o que se pode notar no trecho a seguir:

Creança que entra para as aulas publicas, tenham ou não seus pais meios de attender às despezas com livros e objectos de ensino, é sempre pobre, ou passa a ter essa condição na aula, si a não a tinha fóra da mesma escola.

E, então, de duas uma: ou o professor dá-lhe todos os livros com o attestado de pobreza passado pelos presidentes de conselho e por mim, ou sem elle, e vive em paz com os pais, recebendo d'elles boas referencias e provas de respeito; ou não os dá senão aos [de] reconhecida miserabilidade e, então, ouve logo improperios, censuras contra o Governo e alusões á honestidade dos referidos professores. Em summa, acaba por malquistar-se com as familias das creanças (Relatório do Inspector da $1^{\text {o }}$ Região Escolar, 1899, p. 61 apud HAWAT, 2015, p. 130).

Na documentação aqui examinada, considerando as ocorrências do termo criança pobre e suas variações (moleque ${ }^{3}$, menino/a pobre e aluno/a pobre), no conjunto, o que mais se destacou, seja do ponto de vista quantitativo, seja pelo aprofundamento e variação das temáticas, foi a vinculação entre infância e trabalho. Sandra Pesavento (1994), analisando jornais operários do Rio Grande do Sul, já havia observado esse aspecto. Por exemplo, o jornal Echo Operário, de Porto Alegre, em 1897, denunciava: "Se os capitalistas têm utilizado de preferência os braços femininos, é porque encontram neles - como nos braços das crianças - instrumentos humanos de trabalho por menor preço” (apud PESAVENTO, 1994, p. 60). Um ano antes, outro periódico operário repudiava a exploração do trabalho infantil nas fábricas ao noticiar a morte de um menino de 11 anos: 
Quando deveria ainda andar no colégio, já era obrigado a ganhar um desgraçado salário para ajudar-se a sustentar. Que miserável sociedade esta burguesa. Um pai vê-se obrigado a sacrificar seus inocentes filhos para não vê-los passar fome... (A Razão, 01/05/1896 apud PESAVENTO, 1994, p. 64).

Mas não era apenas nas fábricas que se empregava a mão de obra de crianças. No jornal A Federação aparecem muitos anúncios pedindo moleques como criados para trabalharem em diversas ocupações. Algo que chama a atenção é a pouca idade requisitada nos anúncios, entre 8 e 10 anos:

Imagem 1 - A Federação, 18/03/1885, p. 2

\section{PRECISASE}

alugar, para recalos, um maleque desa 10 annos. Vejase o annancio.
Imagem 2 - A Federação, 18/03/1885, p. 3

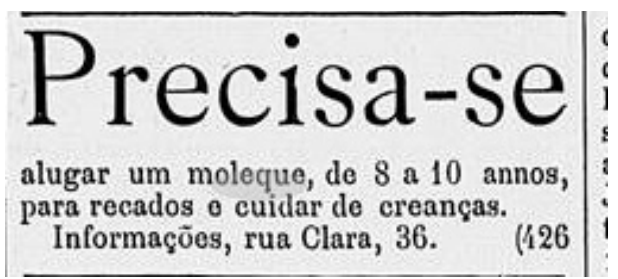

Imagem 3 - A Federação, 26/05/1887, p. 2

$\mathrm{A}^{\prime}$ rua Clara n. 36 , precisa-se contractar uma mulher de idade adiantada e um moleque para cuidar de crianças.

José Carlos da Silva Cardozo (2016, p. 209), ao examinar autos de tutela abertos em Porto Alegre entre 1860 e 1899, também identifica que “considerável número de adultos utilizou como argumento para obter junto ao Estado a tutela de uma criança a colocação dessa numa atividade laboral”, o que indica a naturalização do trabalho infantil no período. Segundo o autor, a justiça valorizava que os pedidos de tutela de um menor de idade indicassem que a criança ou o adolescente iria desenvolver alguma atividade de trabalho na nova residência pois considerava-se que isso contribuiria para que se tornasse um adulto responsável.

Corroborando com essa interpretação temos também a apresentação de motivos para criação, em 1911, da primeira escola municipal pelo Intendente de Porto Alegre José Montaury de Aguiar Leitão. Segundo ele, a principal motivação para abertura das escolas municipais era a existência de crianças que, por terem que trabalhar, só poderiam frequentar as aulas à noite:

Observando que grande numero de creanças, especialmente das que se occupavam no serviço de capina das ruas e das que os progenitores eram empregados da Limpeza Publica, não pudessem ter assistencia escolar, - por não poderem frequentar as escolas elementares mantidas pelo Governo do Estado, por funccionarem durante o dia, e em horas que se entregavam ao trabalho para 
auxiliar com o montante de suas diárias as despezas das respectivas famílias, e assim considerando - resolvi crear uma escola nocturna em um compartimento junto á sede dos serviços de limpeza, a qual denominei "Hilário Ribeiro" [...] (A Federação, 20/10/1924, p. 29).

Além da escola Hilário Ribeiro, que foi fundada em 1911, no ano seguinte começou a funcionar, também em período noturno, a escola municipal Bibiano de Almeida e, seis anos depois, foi instalada a escola Appolinario Porto Alegre. De acordo com o relatório da Intendência Municipal, transcrito no jornal A Federação, essas escolas não eram exclusivas para crianças, mas "accessiveis a todos que as procuram, ainda mesmo de maior de idade ou de nacionalidade extrangeiro, por parecer não se dever negar esse favor aos que desejam aprender as primeiras letras” (A Federação, 20/10/1924, p. 29).

Como se pode notar, as escolas noturnas eram consideradas no período solução socialmente aceitável para a escolarização de crianças para as quais o trabalho era compulsório à sobrevivência. Já no século XIX, durante a vigência do trabalho escravizado, a legislação provincial do Rio Grande do Sul tinha determinado a criação de uma escola noturna. De acordo com seu Regulamento, de 1876:

Artigo $1^{\circ}$ A escola nocturna provincial se destina especialmente ao ensino das classes menos abastadas privadas de freqüentar durante o dia os estabelecimentos de instrucção.

Artigo $2^{\circ}$ Em suas aulas seráõ admittidos os adultos, ingênuos ou libertos, sem outra condição além do procedimento e meio de vida honesto devidamente comprovado.

Artigo $3^{\circ}$ Tambem poderáõ ser admittidos os menores, que, além dos requisitos exigidos pelo artigo precedente, apresentarem consentimento por escripto de seus pais, tutores ou pessoas sob cuja direção viverem (ARRIADA; TAMBARA, 2004).

É possível observar a diferenciação estabelecida em lei dos tipos de escola em função da variação de renda (“classes menos abastadas”). Na província do Rio Grande do Sul, o ensino primário era obrigatório aos indivíduos com idade compreendida entre os 7 e os 15 anos (conforme determinava a legislação de 1871), mas havia previsão de certos grupos "dispensados” da frequência às aulas, entre os quais, por exemplo, aquelas crianças que residiam distantes de uma escola e a infância trabalhadora. Além disso, vale sublinhar o fato de que a escola noturna provincial se destinava também aos ingênuos, como aparece no artigo $2^{\circ}$, modo pelo qual os filhos livres de mulheres escravizadas passaram a ser conhecidos quando foi promulgada a Lei do Ventre Livre. Segundo Heloísa Maria Teixeira (2010, p. 59),

após setembro de 1871, as crianças que nasceram de ventres escravos ganharam a condição de livres, mas, apesar dessa condição, continuaram a viver dentro das escravarias junto com seus familiares cativos. Tendo o proprietário de suas mães o direito de escolher entre os serviços dessas crianças, que seriam prestados a partir dos 8 anos de idade, ou uma indenização pela criação dos mesmos, a grande 
maioria dos senhores escolheu a primeira opção [...]. Vivendo em propriedades escravistas, os filhos livres das escravas foram mantidos em quase sua totalidade na mesma condição servil dos cativos de fato.

Apesar de serem juridicamente livres, os filhos dessas mulheres precisavam trabalhar para seu sustento, visto que nem o Estado nem os senhores de suas mães tinham obrigação de assumir tais encargos.

São muito recorrentes no jornal A Federação as menções à existência de escolas noturnas destinadas a trabalhadores, inclusive crianças ${ }^{4}$. Em 1926, por exemplo, é publicada notícia de uma aula para adultos e crianças analfabetos:

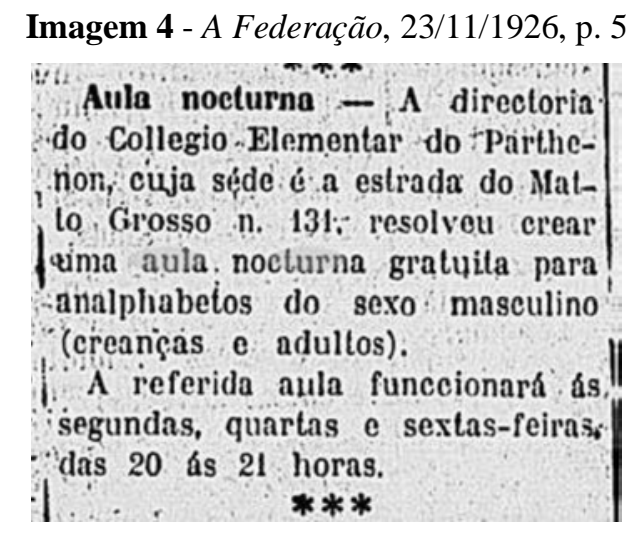

Chama a atenção à coexistência de crianças e adultos que frequentam uma mesma escola. Eliane Peres (2002) já havia identificado situação semelhante em Pelotas, no final do século XIX, ao pesquisar o curso noturno criado pela elite local, na Biblioteca Pública Pelotense, e destinado a ensinar homens e meninos trabalhadores a ler, escrever e contar. Em 1933, a notícia da criação de outra dessas escolas, explicita a gratuidade e são citados os tipos de trabalho realizados pelas crianças às quais essa escola era destinada:

[...] presidida a reunião pelo coronel Agenor Barcellos Feio, foram explicados os motivos da fundação de uma escola noturna gratuita para crianças que vivem vendendo jornais, bilhetes de loteria etc. A idéia feliz e oportuna, dessa partriotica e benemérita fundação coube ao vosso digno correligionário sr. Valdomiro Stefied, funcionario publico (A Federação, 29/11/1933, p. 3).

Essa ideia era louvada pelo jornal e considerada patriótica, demonstrando como a educação das crianças pobres estava, no período, bastante relacionada à ação benemérita.

Outro fato digno de nota é a iniciativa de particulares que criavam cursos noturnos gratuitos destinados a adultos e crianças trabalhadores. É o caso do Ginásio Anchieta, instituição comandada por jesuítas, que em 1912 havia criado um desses cursos. Nos anúncios, publicados em 1914 e 1915, ficam explícitas as intenções: 
Em comemoração à passagem do $3^{\circ}$ aniversário da fundação do curso noturno gratuito para operários e meninos pobres que funcciona no Gymnasio Anchieta haverá hoje ás $16 \mathrm{~h} 30$ um festival que se realizará no salão do centro Catholico ( $A$ Federação, 06/09/1914, p. 16).

Quarta feira, 17 do corrente, no Gymnasio Anchieta, reabre-se o curso noturno gratuito para operários e meninos pobres. Os candidatos deverão ter um emprego que os impossibilite de frequentar aulas diurnas. A matricula acha-se aberta das 19,30 ás 21 horas no Gymnasio Anchieta (A Federação, 10/02/1915, p. 3).

Trata-se de uma iniciativa longeva, visto que, em 1927, no Relatório da Intendência Municipal de Porto Alegre, transcrito no jornal, a iniciativa é elogiada em função do número alto de matrículas: "Da mesma forma cresceu, a matricula do Curso Noturno Gratuito que o Gymnasio mantém desde o anno de 1912. Mais de 300 meninos pobres, victimas do desamparo e da ignorancia, recebem alli conhecimentos uteis á vida” (A Federação, 15/10/1927, p. 44).

De modo geral, para os trabalhadores pobres considerava-se necessária apenas a instrução elementar, como forma de inseri-los na sociedade civilizada, instrumentalizá-los para as atividades laborais e garantir sua formação moral (MORAES, 2000). Em 1897, por exemplo, o Echo Operário denunciava o que acontecia em Rio Grande:

Dizem que a gente de uma fábrica importantíssima desta cidade proibiu ao professor das aulas da mesma fábrica que ensinasse aos filhos dos operários além das quatro operações, leitura e escrita. Os operários não precisavam gramática nem estudos mais profundos do que as quatro operações, disse ele (apud PESAVENTO, 1994, p. 64).

Para além dos saberes curriculares elementares, defendia-se para as crianças pobres apenas a expansão da instrução profissional. Em 1912, há menção à abertura de matrículas no Instituto Técnico Profissional Parobé ${ }^{5}$, criado pela Escola de Engenharia de Porto Alegre. De acordo com a notícia, aquele instituto auxiliaria os mais pobres, pois poderiam aprender um ofício: "Os filhos das classes pobres, querendo fugir á vadiagem corruptora das ruas, encontram no Profissional uma escola altamente patriotica, que os ensine a trabalhar methodicamente” (A Federação, 03/01/1912, p. 1). Note-se, ainda, a existência de uma grande expectativa de que esses jovens, ao se matricularem, aprenderiam também sobre educação moral:

E si é certo que o trabalho possue tambem a virtude de concorrer largamente para educação moral, a passagem pelas officinas deste Instituto deverá contribuir efficazmente para a formação do caracter dos meninos, preparando homens de bem, dignos de si e da sociedade (A Federação, 03/01/1912, p. 1).

Com semelhante finalidade, em 1914, o jornal informava que o governo do estado estava oferecendo uma vaga no Instituto de Agronomia e Veterinária: 
Respondendo a um telegramma que recebera o dr. Borges de Medeiros, pedindo a indicação de um menino pobre a quem o governo concederá matricula gratuita no Instituto de Agronomia e Veterinaria dessa capital, o coronel intendente indicou o menor Jonathas Mario dos Santos [...] (A Federação, 20/06/1914, p. 3).

Em 1925, outro relatório da Intendência Municipal é publicado no jornal. Nele menciona-se, mais uma vez, o Instituto Parobé, reafirmando-se a necessidade do curso noturno para os operários e para aqueles que não conseguem frequentar as aulas diurnas: "Para operários que trabalham durante o dia e para meninos impossibilitados de frequencia diurna, mantém ainda o Instituto Parobé um curso nocturno elementar e de aperfeiçoamento” (A Federação, 15/10/1925, p. 20).

Não apenas ao mundo do trabalho, no entanto, se concentram as menções vinculadas à escolarização das crianças pobres no período. Também ações caritativas têm lugar entre as preocupações das elites. É o caso da caixa escolar, inciativa citada com entusiasmo nas páginas do jornal A Federação, como se verá a seguir.

\section{A caixa escolar: condições para que as crianças pobres frequentem as escolas e estímulo à caridade}

A caridade foi por longo período o modo prevalecente na interação das elites brasileiras na educação da população pobre. Com a República, a filantropia passa, cada vez mais, a coexistir com ações das autoridades públicas preocupadas com o combate do que consideravam problemas gerados pela pobreza. Entre as questões que despertavam preocupação, tanto no século XIX como no XX, estava que o futuro das crianças pobres não representasse riscos ao funcionamento da sociedade burguesa, o que levou à criação de vários asilos, como já mencionamos.

Frederico de Castro Neves (2014, p. 117), analisando as ações de caridade e controle social no Ceará em 1915, ano em que a seca expos à miséria muitos retirantes, evidencia uma corrente de caridade formada pelas elites, não apenas daquele estado, que reforçava

os mecanismos de proteção aos pobres característicos de "regimes não liberais" (Genovese, 1976), cujas relações paternalistas (Thompson, 1998) são baseadas na reciprocidade desigual (Moore Jr, 1987). A caridade reafirmava princípios de manutenção da ordem política tradicional e, ao mesmo tempo, a despolitização do empobrecimento por meio da privatização da assistência social e/ou sua vinculação aos valores cristãos defendidos pela Igreja Católica.

As preocupações em torno da educação das crianças pobres integram esse quadro. Como já indicamos no início deste artigo, tanto os filhos dos pobres sem ocupação definida, como os filhos dos operários, os filhos livres de mulheres escravizadas e também as crianças órfãs, despertavam preocupação das elites, em grande medida pela defesa de seus próprios interesses. Nesse sentido, prevalecia a compreensão de que era preciso educar essas crianças, 
a partir de valores burgueses (desvalorizando suas culturas de origem) e mantê-las sob controle. Assim, vale lembrar, as referências ao problema da infrequência das crianças pobres à escola são comuns nos relatórios da instrução pública ao longo de todo o período imperial e, também, durante a República. Cynthia Greive Veiga (2008, p. 508) ressalta, para o caso da província de Minas Gerais, que "não somente quase todos os relatórios fazem referência à pobreza como também várias correspondências de professores justificavam a ausência dos seus alunos em razão desse fator”.

Nos anos 1920 e 1930, localizamos no jornal A Federação notícia de algumas ações que visavam estimular ou viabilizar a frequência das crianças pobres à escola por iniciativas diversas. Em 1929, por exemplo, há informação sobre a instalação de escolas primárias pelo governo municipal de Bagé e da municipalização do curso ginasial da mesma cidade 6 , indicadas como formas de auxiliar no ensino dos mais pobres:

A installação dos Collegios Municipaes, a municipalisação do Gymnasio Municipal, o Conservatorio de Musica, a instrucção physica, a construcção da praça de desportos, cujo material foi offerecido pelo conterraneo dr. Pardo Santayana, o auxilio oferecido a todo alumno pobre que queria se formar por conta do municipio, cujo credito conseguiu do Conselho [...] (A Federação, 15/04/1929, p. 1).

Em 1933, o jornal noticia uma festa feita pela empresa cine-caxiense para colaborar com o financiamento dos alunos pobres no Colégio Elementar José Bonifácio:

A Empresa do Cine-Caxiense atendendo a solicitação feita pela direção do Colegio Elementar José Bonifacio, gentilmente dedica o espetaculo de $4^{\text {a }}$ feira proxima, em beneficio do "Aluno Pobre" daquele estabelecimento, reinando vivo o entusiasmo para essa festa de caridade (A Federação, 28/09/1933, p. 8).

Esse trecho permite notar como o auxílio à criança pobre estava muito relacionado à caridade dos particulares, pessoas ou instituições. Isso é perceptível também no trecho a seguir, cujo relato ressalta que pessoas saíram às ruas para pedir donativos para os alunos pobres:

Ontem, á tarde, uma comissão composta dos srs. Angelo Fontana, João Mastroti Filho, Jacob Mestri e senhoritas Ilka Fontana, Ancila Borghetti, Ercy Letti, Edith Caretti, Loudes Avilla e Odacira Castro Fortuna, percorreu as principais ruas da vila angariando donativos para o Aluno Pobre. A população local, acolheu com seu obul para auxiliar tão nobre e humanitario programa. (A Federação, 02/10/1933, p. 3).

Menção semelhante acontece em 1935 e se refere à realização de quermesses para arrecadação de fundos destinados à compra de uniformes e calçados: 
Imagem 5 - A Federação, 29/08/1935, p. 7.

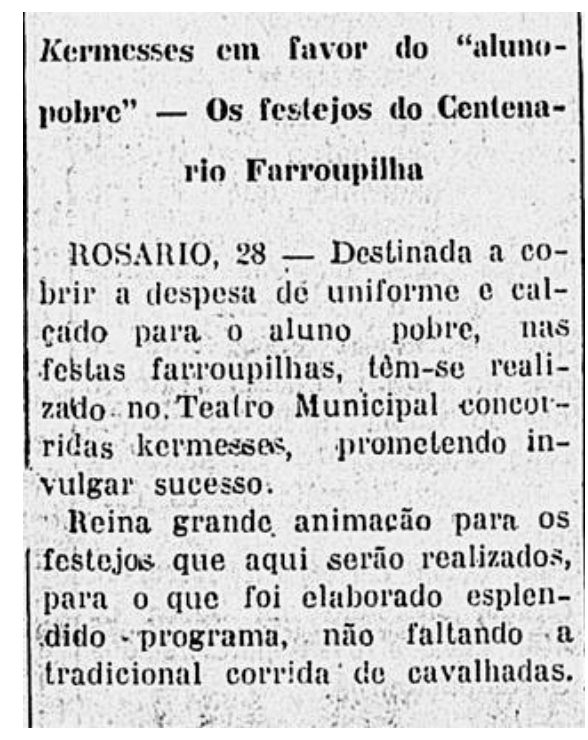

A caixa escolar foi uma das alternativas postas em funcionamento como forma de favorecer a escolarização das crianças pobres ${ }^{7}$. No caso do Rio Grande do Sul, conforme destaca Luísa Grando (2019, p. 455),

a caixa escolar atuou no período de 1917 a 1929 como mecanismo de permanência das crianças pobres na escola através do fornecimento de roupas, calçados, alimentação e transporte, além de contribuir para o desenvolvimento da filantropia dos alunos mais ricos para com os mais pobres.

Embora as primeiras caixas escolares tenham sido criadas em 1917, nos Colégios Elementares de Pelotas, Cruz Alta e Passo Fundo, e muitas tenham sido instaladas entre 1922 e 1923, sua regulamentação data de 1927 . No jornal A Federação, referência à caixa aparece em data anterior à sua instalação em escolas sul-rio-grandenses, anterior mesmo à proclamação da República. É possível notar que o modelo vindo da França é indicado como boa solução. Nesse ano, em 1884, uma matéria é traduzida do jornal francês "Petit Journal" apresentando informações sobre o funcionamento das caixas escolares naquele país e destacando sua criação como iniciativa salutar:

Eis o que dizem e o que pensam os bons educadores que estabelecem as caixas economicas escolares; e estes homens, convencidos pela experiencia, tornam-se os promotores entre os seus visinhos bem depressa êmulos de seus progressos [...] comprehende-se por isso que em certas localidades da França, os pais principiam 
a encarar como incompleta uma escola que ainda não instituio uma caixa economica escolar [...] para muita gente, como para essa creança leviana, a caridade, a generosidade, é o dinheiro dos outros; quanto ao educando econômico, para elle é uma dedicação real, praticada com sacrificio pessoal. Essas dedicações, que fortificam o senso moral, são frequentes nos alumnos das caixas economicas escolares [...] para comprar livros, preparos de aula accudir algumas vezes á familia imprevidente, para qual alguns francos pódem ser os bemvindos para passar um máo dia, e tambem para contribuir para aquellas boas obras que tanto na escola como na familia são um exercício moral, salutar (A Federação, 24/10/1884, p. 1).

Note-se que características da caixa escolar francesa mencionada no jornal em 1884 são similares às das caixas escolares sul-rio-grandenses que serão instaladas depois. Ainda antes desse acontecimento, em 1916, o jornal traz também notícia de uma caixa escolar no interior de Minas Gerais:

Donativos a uma escola - Segundo communicação recebida pela secretaria do interior de Minas Gerais, sr. o Nunziato Schedetino, cavalheiro residente na cidade mineira de Mar de Hespanha, acaba de fazer á caixa escolar daquella cidade de que é presidente, vallioso donativo de $200 \$ 000$.

Esta caixa, que já tem fornecido uniformes, papel, pennas, tinta e outros objectos a mais de 100 alumnos do grupo escolar, possuía ainda em cofre, em 30 de setembro ultimo, 1:067\$822. (Federação, 30/10/1916, p. 3, negrito no original)

Sobre as caixas escolares instaladas no Rio Grande do Sul, a primeira menção data de 1921, quando se anuncia a abertura de uma caixa escolar em Porto Alegre, no Colégio Elementar Souza Lobo. Neste trecho é possível notar as atribuições da caixa escolar, bem como para qual público era destinada: “A contribuição será feita por collecta mensal entre professoras e alumnos tendo a Caixa por fim prover o necessario para as festas escolares e supprir de roupa e calçados aos alumnos cuja pobreza fôr reconhecida” (A Federação, 15/03/1921, p. 5). Nesse mesmo ano é inaugurada uma caixa escolar em Arroio Grande. No anúncio, o objetivo da caixa escolar está assinalado: "Por iniciativa da directora do colegio, foi fundada a caixa escolar para auxiliar a frequencia das creanças pobres. Foi aberta uma lista com esse fim, obtendo valiosos donativos” (A Federação, 28/04/1921, p. 4). Em Bagé, no mesmo ano, há notícia de uma apresentação teatral em prol da caixa escolar do Colégio Elementar da cidade, indicando que os valores arrecadados ajudariam na frequência dos alunos pobres da escola: “[...] está organisado uma bella matinée no theatro Avenida em beneficio da caixa escolar daquelle estabelecimento de ensino, afim de proporcionar os meios ás creanças pobres de frequentarem as aulas” (A Federação, 23/06/1921, p. 4). Em Caxias do Sul também é inaugurada uma caixa escolar indicando seu objetivo de incentivar a frequência dos alunos pobres com sapatos e roupas: “[...] No mesmo acto foi inaugurada a caixa escolar pelos professores do referido collegio, afim de facilitar a frequencia dos alumnos pobres fornecendo-lhes roupas e calçados” (A Federação, 10/09/1921, p. 3). 
Havia duas diferentes carteiras que compunham as caixas escolares. Em 1926, o jornal publica explicação acerca do que as distinguia:

Esta caixa, dividida em duas secções, uma economica e outra beneficente, visa a educação das creanças, moral e economicamente, pois na primeira se ensina a juntar mensalmente com a quantia de 200 réis, uma peculio que começará a render quando atinja 10\$, quantia que é depositada na Caixa de Depositos Particulares do Estado em nome do alumno, a outra com egual quantia mensal, cria-se peculio com que socorrer os alunos necessitados (A Federação,08/09/1926, p. 11).

Como mencionado anteriormente, as caixas escolares no Rio Grande do Sul foram criadas dez anos antes da sua regulamentação em lei. Em 1927, é publicado o Decreto ${ }^{\circ}$ 3.903 que aprova o regimento interno dos estabelecimentos de ensino públicos do estado e nele consta a caixa escolar, detalhando-se seu funcionamento e as obrigações de seus sócios. A divisão em duas carteiras, uma econômica e a outra beneficente, consta aí especificada:

Da carteira economica só serão socios os alumnos do estabelecimento. As contribuições para esta serão, no minimo de 200rs por vez. Entregues as quantias, o thesoureiro dará um recibo provisorio, visado pelo caixa. Quando as contribuições attingirem a 10\$000 rs, passará essa quantia aos depósitos populares do Estado em nome do contribuente, vencendo os juros de accôrdo com o regulamento respectivo (RIO GRANDE DO SUL, 1927).

Além disso, o Decreto explicitava as funções definidas para a caixa escolar:

Art. 46 - Devem ser instituidas nos estabelecimentos de ensino as Caixas escolares, de importancia incontestavel, tendo como objetivo duplo de desenvolver o sentimento altruistico na creança e dar-lhe, ao mesmo tempo, educação civica.

No primeiro caso, cada alumno concorre para o bem estar de seus collegas desprotegidos de fortuna, auxiliando-os, sem alardes, visto que todo beneficio deve ser feito com minimo de constrangimento para quem recebe, tendo, apenas, conhecimento do favor, a directoria da sociedade.

Os outros socios, bem como todas as pessoas extranhas, não terão conhecimento dos nomes dos favorecidos, perdendo o cargo que occupa na directoria da caixa, todo membro que fizer revelações nesse sentido (RIO GRANDE DO SUL, 1927).

Interessante notar que o destaque dado em lei para a função de permitir ocasião para as crianças “desenvolverem o sentimento altruístico” é maior que efetivamente o auxílio dado aos alunos "desprotegidos da fortuna”. Além disso, note-se que a lei sugere pensar que era vexatório receber as contribuições provenientes da caixa escolar, razão pela qual determinava-se sigilo quanto ao nome dos favorecidos. Esses aspectos permitem argumentar que a caixa escolar foi instituída como forma regulamentada em lei de exercício da caridade, mais do que como mecanismo para garantia do direito das crianças pobres à educação. Nesse 
sentido, convêm observar que a caridade se constitui, naquele período, não apenas no caso sul-rio-grandense, “como elemento organizador da relação com os pobres e legitimador da ordem social que naturalizava a pobreza” (NEVES, 2014, p. 118). Havia, ainda, uma outra função designada à caixa escolar pela legislação, que se referia ao estímulo à educação cívica, visto que os alunos participavam de forma ativa das votações e decisões a ela relacionadas:

Art. 46 - [...] No segundo ponto, a educação civica é ministrada de um modo indirecto, habituando os alumnos á escolha independente dos encarregados de seus interesses, para o que serão estimulados pelos professores que os congregarão em torno da sociedade, já ou por meio de exercicios sportivos, já por meio de sessões literárias, festas escolares, etc. [...]

A apuração dos votos será feita com todo cuidado, usando-se do processo do voto escripto em listas assignadas, afim de que cada aluno mostre o desassombro e coragem nas suas opiniões.

Os que não puderem escrever poderão dar voto oral que será levado em consideração pela mesa.

Tendo em vista, pois, as vantagens decorrentes de tão util instrucção, lançam-se as bases dos seus regimentos que devem ser projectados pelos directores dos collegios e discutidos e votados pela assembléa geral de alumnos uma vez organizados em sociedade (RIO GRANDE DO SUL, 1927).

Ao analisar as informações sobre a caixa escolar publicadas nos relatórios estaduais da instrução pública no período de sua vigência, Luísa Grando (2019, p. 464) observa que "é possível perceber uma grande diferença em relação aos valores recebidos, número de sócios e, consequentemente, de alunos auxiliados, dependendo da entrância em que o colégio se qualificava”. Assim, quando os colégios se localizavam nas regiões economicamente mais favorecidas do estado, os valores arrecadados, e consequentemente o auxílio dado aos alunos pobres, eram maiores do que os constatados nas caixas escolares das cidades menores e de regiões menos pujantes. Isso é coerente com o modo de funcionamento da caixa, visto que os valores dependiam das contribuições de seus próprios alunos e comunidade do entorno, e reforça a interpretação de que a principal finalidade da caixa não era garantir a frequência das crianças pobres às escolas.

O jornal também traz algumas notícias sobre os gastos financiados pelas caixas escolares no estado, como nos exemplos a seguir:

A direcção do Collegio Elementar de S. Leopoldo, cuja matricula no corrente anno attingiu 200 alumnos, distribuiu grande numero de capas aos alumnos pobres que frequentam o referido instituto de ensino. Essas capas foram adquiridas por conta da caixa escolar installada naquelle collegio (A Federação, 02/06/1922, p. 5).

O Collegio Elementar de Cruz Alta, que conta com uma matricula de 700 e uma frequencia de 500 alumnos em média, distribuiu roupas para 84 destes, servindose para isso do auxilo da caixa escolar (A Federação, 13/06/1922, p. 5). 
A mistura entre o caráter cívico e caritativo das ações em torno da caixa escolar também é notável na seguinte notícia sobre uma quermesse realizada em prol da caixa escolar em que se menciona a distribuição de comida aos alunos pobres na saída do evento:

A sra. d. Universina Nunes, directora do Collegio Elementar 15 de Novembro, de Bagé, distribuiu aos alumnos pobres, biscoitos, assucar, café, chocolate, meias e calçados, como lembrança das kermesses realisadas no mesmo estabelecimento de sua caixa escolar (A Federação, 13/06/1922, p. 5).

No ano de 1923, é divulgada no jornal uma lei que proíbe que livros sejam fornecidos por meio dos valores arrecadados pela caixa escolar, uma vez que essa era uma atribuição do estado: "A Caixa Escolar não deve fornecer livros aos alumnos, pois o Estado encarrega-se disso” (A Federação, 17/01/1923, p. 14). Em 1929, há notícia de reunião dos membros da caixa escolar de Porto Alegre em que o diretor, Emilio Kemp, afirmava que a iniciativa era indispensável e, para aqueles que pudessem, seria importante contribuir com valores maiores, uma vez que cada nova criança dentro da escola seria novo trabalhador para o Rio Grande do Sul:

Tendo-se em vista que uma creança não gasta em roupa e sapato de typos collegiais mais de 25 mil réis por mez, em média, chegamos a conclusão que a Caixa enviará 400 creanças ás aulas durante o anno. Deante da quantidade de creanças que não frequentam o collegio por falta de roupa esse numero parece pequeno. Pois não é. São mais de 400 alphabetisados que o Estado adquire e que vão trabalhar com maior rendimento para prosperidade do Rio Grande ( $A$ Federação, 11/05/1929, p. 5).

Na proposição de Emílio Kemp há uma intenção redistributiva e o argumento cívico é que se destaca. Segundo ele, apesar de alguns distritos poderem oferecer menos dinheiro que os demais, as caixas escolares dos colégios funcionariam normalmente e poderiam auxiliar com o que a caixa municipal não conseguisse suprir. Poucos dias depois, o jornal publica uma nota sobre a abertura oficial da caixa escolar municipal de Porto Alegre que explicita a intenção de alcance não apenas das crianças do curso primário: “[...] uma instituição de auxílio as creanças pobres, fornecendo-lhes vestimentas para a frequencia aos estabelecimentos de ensino primario e profissional. Aprovada a feliz idéa pela numerosa assistencia [...]” (A Federação, 15/05/1929, p. 4).

Naquele mesmo ano, foi instituída a "Semana da Caixa Escolar" que tinha como objetivo promover a realização de eventos que arrecadassem maiores valores para a caixa escolar municipal de Porto Alegre. As notícias sobre a "semana da caixa escolar" permitem confirmar os objetivos e o modo de funcionamento da caixa. Essas publicações reiteram a feição caritativa das ações na medida em que explicitam os objetivos e a programação da semana: 
A “Semana da Caixa Escolar” organizada por aquella aggremiação de estudantes, terá por fim auxiliar as crianças, que, por falta de recursos, estão impossibilitadas de estudar. A comissão de preparatorianos organizadora da "Semana da Caixa Escolar", tem percorrido a cidade convidando senhoras da nossa sociedade para fazerem parte da grande comissão central (A Federação, 30/05/1929, p. 4).

Interessante observar que aparece com destaque a participação dos Estudantes Preparatorianos e das alunas da Escola Complementar na organização das atividades. Em especial, a participação das senhorinhas e meninas fortalece a dimensão de caridade, visto que, naquele período, a atividade pública aceitável para as moças das elites restringia-se a poucas possibilidades, entre as quais estavam as ações caritativas:

Varios bandos precatórios, formados por senhorinhas e meninas da nossa sociedade, percorrem a cidade, angariando obulos para a "Caixa". Essa cooperação do nosso povo, nos esforços realizados pelo governo para melhorar e ampliar a instrucção, darão fóra de toda duvida, os melhores resultados ( $A$ Federação, 10/06/1929, p. 1).

Chama a atenção, ainda, a decisão de distribuir "cartazes de propaganda por diversos pontos da capital, bondes e cafés”, espaços de circulação das elites no período, e o anúncio de que a "agência dos automóveis da marca 'Auburn'” havia disponibilizado aos estudantes um carro daquela agência para auxiliar nos serviços de preparação da semana da caixa escolar. Há menção, ainda, ao peso que significava ao poder público arcar com as despesas de escolarização dos pobres: "Nem tudo pode prover o poder publico. Em paizes vastos de rara população, como o nosso onde os encargos formidaveis da despeza publica crescem em desproporção com a recceita, a cooperação social é um dever iniludível” (A Federação, 10/06/1929, p. 1). Por fim, é explícita a intenção de "salvar” as crianças da miséria como modo de investir no progresso do país, evitando-se o perigo de que essas crianças se desviassem dos caminhos do trabalho considerado digno por aqueles que escreviam no jornal:

Com a educação vão adquirir os meios que fazem certo o trabalho remunerador. A ignorância e a miseria não os farão felizes. Dar para a instruccção das creanças, é dar para o Brasil. Esses obulos que se depõem no seio da bandeira, a educação multiplicará pela gratidão e pelo esforço dos pequeninos benefiario e reverterão depois, sobre todos, nos fructos de ouro do trabalho, do bem estar e da felicidade (A Federação, 10/06/1929, p. 1).

Ou seja, da caixa escolar esperava-se que colaborasse para o avanço do país, visto que viabilizaria a expansão da ação benéfica da escola:

A Caixa Escolar vem accelerar a nossa marcha em atrazo, porque o ensino elementar é a primeira etapa para attingir os cursos superiores [...]. Mais esplorado do que o colonisado, por motivos históricos, que não cabem aqui assignalar, não 
teve o Brasil para sua formação um núcleo de povoadores resolvido a fundar uma nação forte e livre, idêntico aos puritanos (A Federação, 11/06/1929, p. 1).

O mesmo argumento aparece no anúncio de doação ofertada pela “Associação Protetora do Turf” que visava

[...] concorrer para a manutenção, nas aulas publicas, de certo numero de creanças sem recursos, que assim, receberão a luz redemptora da instrucção, concorrendo, mais tarde, para a grandeza economica do nosso querido Rio Grande do Sul, e diminuindo o peso morto dos analphabetos que tanto nos oprime [...] (A Federação, 18/06/1929, p. 4).

Ao final da semana da caixa escolar, foi realizada uma celebração, em que os estudantes preparatorianos receberam uma placa de mérito e que contou com a presença do presidente do estado, Getúlio Vargas. Finalizam-se assim as notícias relacionadas à $1^{\circ}$ semana da caixa escolar municipal de Porto Alegre no ano de 1929. Notícia publicada em 1931, indica que semelhante evento aconteceu nos dois anos seguintes:

[...] como tem sido feito nos annos anteriores, a Escola Normal realisará de 5 a 12 de outubro proximo, a semana da Caixa Escolar de Porto Alegre, com finalidade de angariar donativos para essa instituição que vem mantendo o Instituto Protasio Alves. Durante a semana serão realizadas varias festas escolares com pronunciado cunho educativo, sendo a primeira o Concurso $O$ Sorriso destinado ás crianças de 4 a 8 annos e que tem por fim diffundir os habitos de hygiene relativamente á conservação dos dentes (A Federação, 21/09/1931, p. 4).

\section{Considerações finais}

A polissemia do termo pobre na documentação histórica sugere a pertinência de se aguçar o olhar investigativo a fim de melhor compreender as especificidades dos projetos de escolarização da população pobre no Brasil. Destinatárias de ações caritativas e de proteção, as crianças pobres também foram alvo dos anseios de controle e contenção provenientes, em larga medida, do temor das elites liberais pelos supostos riscos que a pobreza representava à ordem social burguesa.

A análise das publicações no jornal A Federação, que circulou no Rio Grande do Sul entre 1884 e 1937, evidenciou estreita relação entre notícias sobre a escolarização das crianças pobres, o trabalho infantil e as ações caritativas. A pobreza é, nesse enquadramento, dissociada de seu aspecto socialmente estrutural e a questão da cidadania, em lugar de ser enunciada como direito de todos, apresenta-se matizada em função das diferenças de classe social. Assim, como se percebe na análise das fontes históricas, a escolarização das crianças pobres não é mencionada como defesa de um direito subjetivo fundamental, mas como ação 
restrita à funcionalidade que o acesso aos estudos por esse grupo populacional poderia ter na arquitetura elitista de uma sociedade marcada pela desigualdade estrutural.

\section{Notas}

1. Este trabalho vincula-se ao projeto interinstitucional (UFRGS, UNICAMP, USP, UFPI) "Exclusão escolar na história brasileira: persistências e resistências (1920-2020)”, financiado pelo CNPq (processo n 420799/2018-4).

2. Para este estudo, foram consultados os exemplares disponibilizados em formato digital na Hemeroteca da Biblioteca Nacional (disponível em https://bndigital.bn.gov.br/hemeroteca-digital/). Utilizamos como motor de busca os termos: aluno(a) pobre, escola noturna e caixa escolar.

3. Alguns estudos têm indicado que o termo moleque, palavra oriunda do quimbundo, cujo significado original era filho pequeno, passa a designar, no Brasil colonial, os meninos escravizados (LEITE, 2001). No jornal A Federação esse termo associa-se recorrentemente a uma criança desprezível, como se nota no exemplo a seguir: "Eu - fique certo --, não darei reposta a esse moleque de becco, esse lazaro miserável” (A Federação, 09/05/1892, p. 1). Há ainda a veiculação de histórias e notícias em que o moleque está associado à imoralidade, provocando intrigas domésticas (como no conto “O demônio familiar”, publicado em 30/07/1923), ou ao crime.

4. Para o aprofundamento dessa questão ver artigo intitulado "Saberes ensinados, públicos pretendidos e intencionalidades nos primórdios da escola noturna (Rio Grande do Sul, Brasil, 1884-1937), de autoria de Natália Gil e Luísa Grando, a ser publicado proximamente.

5. Para mais informações sobre essa instituição, ver Stephanou (1990).

6. Para informações sobre a municipalização de ginásios em Porto Alegre no mesmo período, ver Gil e Popiolek (2019).

7. Para informações sobre a caixa escolar em outros estados do Brasil, ver Rosana Areal de Carvalho e Fabiana de Oliveira Bernardo (2012), que examinaram o caso de Minas Gerais, e Sélia Ana Zonin, Vera Lúcia Gaspar da Silva e Marília Gabriela Petry (2018), que analisam a documentação referente a Santa Catarina.

\section{Referências}

A FEDERAÇÃO. Orgam do Partido Republicano. Porto Alegre, 1884. A FEDERAÇÃO. Orgam do Partido Republicano. Porto Alegre, 1916. A FEDERAÇÃO. Orgam do Partido Republicano. Porto Alegre, 1921. A FEDERAÇÃO. Orgam do Partido Republicano. Porto Alegre, 1922. A FEDERAÇÃO. Orgam do Partido Republicano. Porto Alegre, 1923 A FEDERAÇÃO. Orgam do Partido Republicano. Porto Alegre, 1926. A FEDERAÇÃO. Orgam do Partido Republicano. Porto Alegre, 1929. A FEDERAÇÃO. Orgam do Partido Republicano. Porto Alegre, 1931. A FEDERAÇÃO. Orgam do Partido Republicano. Porto Alegre, 1933. A FEDERAÇÃO. Orgam do Partido Republicano. Porto Alegre, 1935.

A RAZÃO. Porto Alegre, 1896.

ALMEIDA JÚNIOR, A.. O hiato nocivo na vida legal dos menores. Revista Educação, v. 1 n. 1, mar 1933.

ARRIADA, Eduardo; TAMBARA, Elomar (Orgs.). Leis, atos e regulamentos sobre educação no período imperial na província de São Pedro do Rio Grande do Sul. Brasília: INEP/SBHE, 2004. [Coleção Documentos da Educação Brasileira]. 
CARDOZO, José Carlos da Silva. As crianças no Juízo dos Órfãos de Porto Alegre. In: CARDOZO, José Carlos da Silva et al. História das crianças no Brasil meridional. São Leopoldo: Editora Oikos, 2016. p. 194233.

CARVALHO, Rosana Areal de; BERNARDO, Fabiana de Oliveira. Caixa Escolar: instituto inestimável para execução do projeto da educação primária. Educação em foco, Juiz de Fora, v.16, n. 3, p. 141-158, set 2011/fev 2012. Disponível em: https://www.ufjf.br/revistaedufoco/files/2012/08/Texto-061.pdf Acesso em 23 de abr. de 2021.

CHALHOUB, Sidney. Cidade febril. Cortiços e Epidemias na Corte Imperial. São Paulo: Companhia das Letras, 1996.

DUMONT, Martine. Le succès mondain d'une fausse science: la physiognomonie de Johan Kasper Lavater. Actes de la recherche en sciences sociales, n. 54, p. 2-30, set. 1984.

ECHO OPERÁRIO. Rio Grande, 1897.

FAURE, André. Classe malpropre, classe dangereuse? Quelques remarques à propos des chiffoniers parisiens au XXe siecle et leurs actes. Recherches, n. 29, p. 79-102, dez. 1977.

GIL, Natália de Lacerda; POPIOLEK, Carine Ivone. "É sempre de utilidade pública qualquer medida que venha estimular as iniciativas em prol do desenvolvimento do ensino": ação pública e particular na escolarização de Porto Alegre (1897-1942). Revista de História e Historiografia da Educação, v. 3, n. 8, p. 113-134, mai.-ago. 2019.

GRANDO, Luísa. A caixa escolar para a filantropia discente e a manutenção da frequência na escola: origem e desenvolvimento no Rio Grande do Sul (1917-1929). Anais do 250 Encontro ASPHE - História da educação e democracia: desafios e conquistas, Bagé, 2019.

GENOVESE, Eugene. Roll, Jordan, Roll: the world the slaves made, New York: Vintage Books, 1976.

HAWAT, Joseane Leonardi Craveiro El. "Os saberes elementares matemáticos nas escolas isoladas de Porto Alegre: Avaliações, programas de ensino e livros escolares (1873-1919). Porto Alegre: UFRGS, 2015. 206 f. Dissertação (Mestrado em Educação) - Programa de Pós-Graduação em Educação, Faculdade de Educação, Universidade Federal do Rio Grande do Sul, Porto Alegre, 2015.

HOUAISS, Antônio; VILLAR, Mauro de Salles. Dicionário Houaiss da Língua Portuguesa. Rio de Janeiro: Objetiva, 2009.

KUHLMANN JUNIOR, Moysés. Educando a infância brasileira. In: LOPES, Eliane Marta Teixeira, FARIA FILHO, Luciano Mendes de, VEIGA, Cynthia Greive (orgs.). 500 anos de educação no Brasil. Belo Horizonte: Autêntica, 2007. p. 469 -496.

LEITE, Miriam L. Moreira. A infância no século XIX segundo memórias e livros de viagem. In: Freitas, Marcos César de. (Org.) História social da infância no Brasil. 3 ed, São Paulo: Cortez, 2001. p. 19-52

LIMA, Ana Laura Godinho. A “criança problema” na escola brasileira: análise do discurso pedagógico. Curitiba: Appris, 2018.

LUCHESE, Terciane. História da obrigatoriedade escolar no Rio Grande do Sul. In: VIDAL, Diana Gonçalves; SÁ, Elizabeth Figueiredo de; SILVA, Vera Lucia Gaspar da (Orgs.). Obrigatoriedade escolar no Brasil. Cuiabá/MT: EDUFMT, 2013. p. 275-301.

MOORE JR, Barrington. Injustiça: as bases sociais da obediência e da revolta. São Paulo: Brasiliense, 1987.

MORAES, Carmen Sylvia Vidigal. A normatização da pobreza: crianças abandonadas e crianças infratoras. Revista Brasileira de Educação, n. 15, p. 70-96, set.-dez. 2000. Disponível em: https://www.scielo.br/j/rbedu/a/NghGkkNVTXK7N4Q5rWHMrQy/?lang=pt Acesso em: 23 de abr. de 2021.

NEVES, Frederico de Castro. Caridade e controle social na Primeira República (Fortaleza, 1915). Estudos Históricos, v. 27, n. 53, p. 115-133, jan.-jun. 2014. Disponível em: https://doi.org/10.1590/S010321862014000100006 Acesso em 23 de abr. de 2021. 
PERES, Eliane. “Templo de Luz”: Os cursos noturnos masculinos de instrução primária da Biblioteca Pública Pelotense (1875-1915). Porto Alegre: UFRGS, 2002. 178 f. Dissertação (Mestrado em Educação) - Programa de Pós-Graduação em Educação, Faculdade de Educação, Universidade Federal do Rio Grande do Sul, Porto Alegre, 2002.

PESAVENTO, Sandra Jatahy. Os pobres da cidade. Porto Alegre: Editora da Universidade/UFRGS, 1994.

PINTO, Luiz Maria da Silva. Diccionario da Lingua Brasileira por Luiz Maria da Silva Pinto, natural da Provincia de Goyaz. Na Typographia de Silva, 1832. Disponível em: https://digital.bbm.usp.br/view/?45000038026\&bbm/5414\#page/1/mode/2up Acesso em: 03 de nov. de 2020.

RIO GRANDE DO SUL. Decreto no 3.903, de 13 de outubro de 1927. Aprova o regimento interno dos estabelecimentos de ensino público do Estado, 1927.

RIO GRANDE DO SUL. Lei n 1.046, de 20 de maio de 1876. Regulamento da Instrução Pública, 1876.

RIO GRANDE DO SUL. Leis, Actos e Decretos do Governo do Estado do Rio Grande do Sul 1897. Porto Alegre: Officinas Typogr. de Echenique irmãos \& Cia, 1907.

RIZZINI, Irma; GONDRA, José Gonçalves. Higiene, tipologia da infância e institucionalização da criança pobre no Brasil (1875-1899). Revista Brasileira de Educação, v. 19, n. 58, p. 561-584, jul.-set. 2014.

RÜCKERT, Fabiano Quadros. Olhares sobre a pobreza e a urbanização no Brasil na transição do século XIX para o XX: uma prospecção bibliográfica. In: RÜCKERT, Fabiano Quadros; SILVA, Jonathan Fachini da; CARDOZO, José Carlos da Silva; CESAR, Tiago da Silva (Orgs.). Histórias da Pobreza no Brasil. Rio Grande: Ed. da FURG, 2019. p. 317-346.

SANTOS, Jailson Alves dos. A Trajetória da Educação Profissional. In: Lopes, Eliane Marta T.; Faria Filho, Luciano Mendes; Veiga, Cynthia Greive. (Org.). 500 Anos de Educação no Brasil. $3^{\mathrm{a} e d . B e l o}$ Horizonte/MG: Autêntica, 2003, v. único, p. 205-224.

SANTOS, Milton. A pobreza urbana. 3 ed. São Paulo: Edusp, 2013.

STEPHANOU, Maria. Forjando novos trabalhadores: a experiência do ensino técnico-profissional no Rio Grande do Sul (1890-1930). 1990. Dissertação (Mestrado em Educação). Universidade Federal do Rio Grande do Sul, Porto Alegre, 1990.

TEIXEIRA, Heloísa Maria. Os filhos das escravas: crianças cativas e ingênuas nas propriedades de Mariana (1850-1888). Cadernos de História, v. 11, n. 15, p. 58-93, 31 out. 2010. Disponível em: https://doi.org/10.5752/P.2237-8871.2010v11n15p58 Acesso em 23 de abr. de 2021.

THOMPSON, Edward Palmer. Costumes em comum: estudos sobre a cultura popular tradicional. São Paulo: Companhia das Letras, 1998.

VEIGA, Cynthia Greive. A produção da infância nas operações escriturísticas da administração da instrução elementar no século XIX. Revista Brasileira de História da Educação, v.5, n. 1 [9], p. 73-107, jan-jun, 2005. Disponível em: https://periodicos.uem.br/ojs/index.php/rbhe/article/view/38657 Acesso em: 23 de abr. de 2021.

VEIGA, Cynthia Greive. Escola pública para negros e pobres no Brasil: uma invenção imperial. Revista Brasileira de Educação, v. 13, n. 39, p. 502-516, set.-dez. 2008. Disponível em: https://doi.org/10.1590/S1413-24782008000300007. Acesso em: 23 de abr. de 2021.

VEIGA, Cynthia Greive. Crianças pobres como grupo outsider e a participação da escola. Educação \& Realidade, v. 42, n. 4, p. 1239-1256, out.-dez. 2017. Disponível em: https://doi.org/10.1590/2175623664210. Acesso em: 23 de abr. de 2021.

VIDAL, Diana Gonçalves; SÁ, Elizabeth Figueiredo de; SILVA, Vera Lucia Gaspar da (Orgs.). Obrigatoriedade escolar no Brasil. Cuiabá/MT: EDUFMT, 2013.

ZONIN, Sélia Ana; SILVA, Vera Lucia Gaspar da; PETRY, Marilia Gabriela. Assistência à infância escolarizada: a caixa escolar em cena. Revista Brasileira de História da Educação, Maringá, v. 18 (48), 
p. 1-27, abril/junho. 2018. Disponível em: https://doi.org/10.4025/rbhe.v18.2018.e007 Acesso em: 23 de abr. de 2021

\section{Correspondência}

Natália Gil: Doutora em Educação pela Universidade de São Paulo (USP). Professora na Faculdade de Educação da Universidade Federal do Rio Grande do Sul (UFRGS) e coordenadora do projeto de pesquisa interinstitucional (UFRGS, UNICAMP, USP, UFPI) "Exclusão escolar na história brasileira: persistências e resistências (1920-2020)”, financiado pelo CNPq (processo no 420799/2018-4). Lider do grupo de pesquisa "História da escolarização no Brasil: políticas e estudos especializados" (dgp.cnpq.br/dgp/espelhogrupo/37021).

ORCID: 0000-0002-0818-4858.

E-mail: natalia.gil@ufrgs.br

Luísa Grando: Estudante de Pedagogia na Universidade Federal do Rio Grande do Sul (UFRGS), realiza Iniciação Científica com bolsa BIC/UFRGS desde 2018 no grupo de pesquisa "História da escolarização no Brasil: políticas e estudos especializados” (dgp.cnpq.br/dgp/espelhogrupo/37021).

ORCID: 0000-0002-3561-7698.

E-mail: luisa.orfali@gmail.com

Texto publicado em Currículo sem Fronteiras com autorização das autoras. 